\title{
OPERÁRIOS E PARTICIPAÇÃO NO INÍCIO DA REPÚBLICA: $O$ caso de Pelotas e Rio Grande
}

Beatriz Ana Loner ${ }^{1}$

O movimento operário na zona sul do Estado gaúcho teve, em termos regionais, sua fase mais importante na primeira década da República, em fins do século passado. Foi então que surgiram, nos dois núcleos populacionais mais importantes - Pelotas e Rio Grande jornais socialistas, associações operárias e um movimento organizado o suficiente para produzir algumas das principais greves do período, ao lado de algumas outras manifestações - "meetings" e comemorações de $1^{\circ}$ de Maio - de impacto na sociedade. Neste artigo serão analisados apenas alguns aspectos deste movimento, como sua capacidade associativa e as mobilizações ocorridas.

Pelotas e Rio Grande, no século passado, eram cidades de forte desenvolvimento industrial, rivalizando com Porto Alegre. A industrialização de Rio Grande ocorreu com base em grandes empresas de tecidos, produtos alimentícios e fumos, incrementando-se extraordinariamente justamente nos anos iniciais da República. Quanto a Pelotas, sua grande riqueza eram as charqueadas, mas também possuía uma infinidade de pequenas fábricas, dos mais variados tipos, ao lado de algumas maiores, como de calçados, chapéus, farinha, sabão e ve-

Professora assistente do Departamento de História e Antropologia da UFPel e aluna do curso de Doutorado em Sociologia da UFRGS, desenvolvendo a pesquisa Classe e identidade operária: Pelotas 1889-1937, sob a orientação do prof. Dr. Antonio David Cattani. 
las. Muitos desses estabelecimentos ainda eram apenas manufaturas, mas já se destacavam aquelas que possuíam motores e cujo trabalho se mecanizava rapidamente. Esse parque industrial sofria com a concorrência do contrabando via fronteira, o que tornava pouco competitivos seus produtos no mercado local, obrigando muitas indústrias (de tecidos, chapéus, calçados) a dedicar-se à exportação. A concessão de uma taxa de importação extremamente baixa para o comércio de Porto Alegre em 1888, afetou todo o Estado, prejudicando ainda mais a nascente indústria e diminuindo o volume da produção e do emprego. Esta tarifa foi a responsável direta pelas primeiras tentativas de articulação de interesses industriais, de que foram exemplo as Ligas Operárias ou associações assemelhadas, surgidas nas três cidades mais importantes do estado: Porto Alegre, Pelotas e Rio Grande. Com a baixa dos preços dos produtos importados muitas empresas correram o risco de fechar, diminuindo sua produção. A Revolução Federalista de 1893 também trouxe graves consequências, especialmente quanto ao suprimento de matérias primas necessárias à produção, acarretando o fechamento de empresas ou a redução do número de operários.

O município de Pelotas possuía em 1891 uma população total de 37.246 pessoas, enquanto Rio Grande em 1888, tinha uma população de 20.277 pessoas $^{2}$. Na zona urbana de Pelotas moravam em 1891, 4.160 estrangeiros $(18,1 \%)$, dos quais aproximadamente a metade deveria corresponder a portugueses, e a outra metade, compunha-se, em ordem decrescente, de italianos, uruguaios, espanhóis, alemães e franceses ${ }^{3}$. A presença alemã na cidade era pequena, embora os ale-

2 Os dados estatísticos sobre Pelotas foram retirados do Boletim apresentado à Intendência Municipal da cidade de Pelotas em sessão de 12 de maio de 1891, por Euclides B. de Moura, diretor da repartição de Estatística da mesma Intendência. Pelotas, Livraria Universal, 1891. Os dados de Rio Grande foram colhidos no jornal A Pátria de 21/7/1888. Contudo, a diferença de três anos entre os dois recenseamentos prejudicam a comparação, em detrimento de Rio Grande. Mesmo sobre os dados de Pelotas, o próprio diretor da secçāo de Estatística considerava que houve falhas na coleta de dados, motivo pelo qual preferia trabalhar com o dado de 40.000 pessoas para a populaçāo total do município e 25.000 para a zona urbana.

3 Os dados sobre a distribuição por nacionalidades dos estrangeiros em Pelotas foram retirados de: ANJOS, Marcos Hallal. - Estrangeiros e modernização: a cidade de Pelotas no último quartel do século XIX., PUCRS: Porto Alegre, 1996 (dissertação de mestrado em História), p. 55 e 57. 
mães fossem um contingente expressivo entre os moradores das colônias municipais. Os negros e mestiços somavam 7.035, ou seja $30,7 \%$ do total dos moradores urbanos.

Em Rio Grande haveria, em 1888, 3.710 estrangeiros na população total do município, sendo quase a metade destes portugueses, vindo a seguir italianos, alemães, franceses e ingleses. Estes estrangeiros corresponderiam a $18,3 \%$ da população total, enquanto 5.573 são negros ou pardos ( $27,48 \%)$. Embora em Rio Grande se trate com dados sobre a população total do município e, em Pelotas, sobre a população urbana, é possível afirmar que Rio Grande possuía mais estrangeiros, proporcionalmente, que Pelotas, pois na primeira cidade a população estrangeira concentrava-se naturalmente na cidade, não havendo nenhum projeto colonizatório que vingasse no município de Rio Grande na época ( e, portanto, o percentual de 18,3\% apresenta-se mais diluído do que se lidássemos apenas com os dados da zona urbana). Além disso, na década de 1890 , a cidade e sua indústria desenvolveram-se enormemente, inclusive importando diretamente mãode-obra estrangeira, como a Ítalo-Brasileira e a fábrica Poock de fumos.

É difícil estimar a população operária naquele momento. Em Rio Grande, o jornal Echo Operário (24/10/97) considerava serem ao redor de 8.000 a 10.000 pessoas aqueles que viviam de seu próprio trabalho, mas neste número estavam incluídos donos de oficinas e artesãos autônomos. Infelizmente, não há estimativas ou projeções sobre Pelotas.

A presença estrangeira entre a população operária de Rio Grande era mais visível do que em Pelotas, pois sabe-se que algumas fábricas só utilizavam essa mão-de-obra ou, pelo menos, possuíam seções inteiras compostas de imigrantes. Para Pelotas, há dados indicando que o número de trabalhadores nacionais era maior, não só nas charqueadas, que concentravam este trabalhador, mas também pelo seu emprego em várias fábricas ${ }^{4}$. $\mathrm{O}$ elemento imigrante era mais facilmente encontrável nas centenas de oficinas e pequenas manufaturas existentes. Também houve casos de empresas que importavam traba-

4 As referências encontradas sobre a nacionalidade dos operários são esparsas, pois este dado é inexistente, aparecendo raramente nos jornais apenas quando falam de acidentes ou conflitos envolvendo operários. Entretanto, às vezes, ao descreverem fábricas, aparecem informações sobre a nacionalidade dos operários. 
lhadores especializados, mas, como se constituíram em projetos de menor envergadura econômica em relação àqueles de Rio Grande, o número destes trabalhadores foi, conseqüentemente, menor.

\section{Características associativas}

Uma forte tradição associativa fez com que estes elementos cedo se congregassem em entidades mutualistas e beneficentes, bailantes, carnavalescas, musicais, literárias e teatrais, estas últimas em número elevado. Pelotas se destacava pelo grande número de entidades existentes.

Entre estas, a cidade abrigou as duas primeiras entidades de representação classista ${ }^{5}$ - patronal e operária - do Estado. O Centro Agrícola Industrial, fundado em 25/8/1887, pretendia representar os interesses de estancieiros, charqueadores e industriais. Entidade forte, criada num momento especialmente delicado e de grandes transformações sociais, como a Abolição, e cuja diretoria era dominada pelos charqueadores, o Centro, através de seu jornal ( O Sul do Brasil ) e do editor deste, João da Costa Fortinho, desempenhou importante papel no incentivo à industrialização, à introdução de técnicas modernas na agricultura e ao desenvolvimento do associativismo na região. Contudo, este Centro desfez-se no $2^{2}$ semestre de 1888 , talvez porque fossem muito amplos e contraditórios os interesses que procurava representar ${ }^{6}$.

5 Também é de Pelotas a primeira entidade exclusivamente de representação dos interesses agro-pecuários do Estado, a Sociedade Agrícola Pastoril do Rio Grande do Sul, fundada em 12/10/1898 (fonte: Estatutos da Sociedade Agrícola Pastoril do Rio Grande do Sul. Pelotas: Livraria Universal, 1898).

6 Como indicativo dessa assintonia, sua última luta foi contra a tarifa especial. Ora, esta tarifa penalizava as indústrias da região, especialmente aquelas de tecidos, chapéus e sapatos, mas não ameaçava os interesses dos estancieiros ou charqueadores. Contudo, o editor do jornal e secretário do Centro se jogou fortemente na luta contra a tarifa e isso coincide com o deflagrar de um processo de indisposição de setores da elite política pelotense contra ele, representados pelo jornal $\mathrm{Di}$ ário de Pelotas, vinculado ao Partido Liberal (Diário de Pelotas, 24/9/1888). Saindo daqui, João da Costa Fortinho vai promover a fundação do Centro Industrial Agrícola de Rio Grande e depois vai continuar seus esforços no sentido do associativismo industrial no Rio de Janeiro (OP, 1/7/1897). Ver, a respeito, LO- 
Em 31/3/1889 é criado o Congresso Operário, órgão que pretendeu representar os interesses vinculados às indústrias da região, abrangendo em sua composição patrôes e empregados. Em 21/7/1890, ele se transformou na Liga Operária de Pelotas, a qual vai dominar a representação operária na cidade ao longo da década. Essa entidade surgiu na esteira da luta contra a tarifa especial. Mais ou menos na mesma época surgiram entidades assemelhadas em Rio Grande (Centro Industrial Agrícola - 15/10/1888) e Porto Alegre (Liga Operária Industrial $-13 / 1 / 1889)^{7}$. Embora não haja notícia de que a associação de Rio Grande comportasse operários, aquela de Porto Alegre assim procedia, pois constava de sua primeira diretoria Nicolau Tolentino da Soledade, o qual participará da Liga Operária Internacional de 1896. Entretanto, exceção feita à pelotense, as outras duas não subsistiram por muito tempo. A Liga Operária de Pelotas, com hegemonia burguesa, dominará o movimento associativo local por duas longas décadas, em que pese outras tentativas (União Operária Internacional - 12/12/97 - e Sociedade União Operária - 13/8/1905) de estabelecimento de entidades representativas compostas exclusivamente de assalariados. Somente na segunda década do século a Liga passará à influência anarquista, mantendo-se ativa, aproximadamente, até 1933 .

Em Rio Grande, depois de algumas tentativas falhadas, surgiu em fins de 1893 (25/12) a Sociedade União Operária (SUO), órgão classista que pretendia congregar todos os trabalhadores manuais e mantinha um viés de resistência e incentivo à luta econômica dos trabalhadores (seu estatuto incluía um capítulo sobre o apoio às greves e a adoção de uma contribuição extra por associado para custear os festejos de $1^{\circ}$ de Maio). A representação proporcional das forças políticas na direção da entidade, através do preenchimento pela chapa minoritária dos segundos cargos na diretoria, foi uma prática vigente desde meados da década, e contribuiu para evitar o monopólio de sua

NER, Beatriz. O pensamento da elite agrária pelotense em 1888: a revista Sul do Brasil.Pelotas, 1995, mimeografado.

7 Segundo os jornais A Pátria, 15/10/1888, e Onze de Junho, 17/1/1889. A associação de Porto Alegre, na verdade, pretendia constituir-se num partido, cujas principais reivindicações seriam: protecionismo, vias de comunicação, extensâo do direito do voto, imposto equitativo e policiamento. Em 9 e 11/12/1890 o A Pátria traz novamente notícias da existência de uma Liga Operária em Porto Alegre, que realizou assembléia no São Pedro, reunindo "70 operários e industriais". 
direção apenas por um grupo político. A entidade terá, nestes anos, uma participação expressiva, apoiando movimentos grevistas e representando o conjunto da população em alguns momentos, como no encaminhamento de lutas contra a carestia de vida e na campanha pela construção dos molhes da barra do Rio Grande. Manteve montepio, assistência mútua, escola e grupo teatral e, embora posteriormente sua importância decresça em termos de representação de classe, o movimento operário da cidade de Rio Grande encontrará nesta entidade um poderoso ponto de apoio logístico e material para suas atividades até 1964, quando foi definitivamente fechada pelo movimento golpista de março daquele ano.

Ainda como entidades representativas de categorias ${ }^{8}$, com caráter mutualista, houve em Rio Grande duas tentativas de associações, por parte dos tipógrafos - S. Tipográfica Rio Grandense (13/1/1890) e União Tipográfica (12/10/1899). O patronato desenvolveu algumas entidades como o Centro Industrial Agrícola (15/10/888) e o Grêmio Artístico Industrial, os quais se fundiram em 20/5/1890. O Club Caixeral (3/5/1895), Club Comercial (existente pelo menos desde 1885) e a Sociedade União Comercial dos Varejistas completavam o quadro das entidades classistas. O Grêmio dos Jornalistas (17/9/98) pretendia congregar todos os envolvidos nas redações dos jornais, com um propósito político e ético de normatização jornalística, mas durou pouco tempo, devido ao clima de radicalização e sectarismo dominante.

Em Pelotas criou-se maior número de entidades, tanto operárias quanto patronais. Entre as últimas, existiram a Liga (que cumpre muito mais o papel de representação política patronal do que operária no período), o já citado Centro Agrícola Industrial, o Centro Cooperador dos Fabricantes de Calçados (7/8/1888), o Club Comercial, Club do Comércio e Associação Comercial, esta última existente desde 1873, o Club Comercial dos Varejistas (maio de 1892 - na verdade eram atravessadores de gêneros coloniais) e o Club dos Curtidores (existe em 1890). Também tentou-se a criação de uma associação de donos de jornais (22/5/89), mas a iniciativa não se concretizou.

8 Os números entre parênteses correspondem à data de fundação da entidade, baseada em consulta realizada em estatutos e jornais diários das duas cidades, conforme consta de relação no final do artigo. Não será colocada a fonte em cada momento para evitar o acúmulo de citaçōes. 
Do lado operário, além da Liga, fundou-se em 12/12/1897 a Sociedade União Operária Internacional, exclusivamente de assalariados, com forte base entre a categoria dos chapeleiros. O Club Caixeiral (25/12/79), surgido na luta pelo fechamento das portas aos domingos, era a entidade mais antiga existente, surgindo, na mesma época, o Grêmio dos Guarda-Livros, de existência efêmera. Os tipógrafos fundaram várias entidades: em tempos mais recuados houve o Grêmio dos Tipógrafos (1881) e depois a Sociedade Beneficente União Tipográfica Guttemberg, fundada a primeira vez em 29/6/88 e a segunda em 17/9/99, sendo desativada nos anos 70 do nosso século. Os chapeleiros tiveram algumas tentativas de organização, duas das quais se transformaram em entidades: a Sociedade União e Fraternidade dos Operários Chapeleiros, atuante em 1888/89, de composição mista, e o Centro Operário $1^{\circ}$ de Maio (agosto de 1899), de curta existência, mas exclusivo para trabalhadores assalariados. Boleeiros (18/12/1897), operários marmoristas (27/12/1890) e cozinheiros (6/6/1891) também formaram organizações beneficentes próprias nesse período.

Em termos mais amplos, houve entidades beneficentes congregando várias categorias profissionais, como em Pelotas a S. B. Harmonia dos Artistas (artesãos: 25/3/81 ou 5/9/81); a A. B. Classes Laboriosas (maçons - 10/10/80); a S. B. Socorro dos Artistas (13/6/90), a S. S. Amparo Mútuo (1/7/90), a S. B. Fraternidade Artística e a Feliz Esperança (10/10/80), ambas de negros; e a S. B. União Humanitária (22/12/98 - dissidência da Harmonia dos Artistas). Em Rio Grande existiram as Classes Laboriosas (1890), a Sociedade Protetora das Classes Proletárias (6/7/97), ambas com forte influência maçônica, e a Sociedade Cooperativa Filhos do Trabalho (negros, 1890). Embora o caráter mutualista destas associações, elas cumpriam o papel de representação de classe, várias delas fazendo-se presentes nos momentos de festas e manifestações conjuntas das categorias.

Havia ainda as Caixas de Socorros de fábricas ${ }^{9}$, como a dos operários da fábrica Cordeiro Wiener sus. (chapeleiros - 22/5/1892), e

9 Muitos autores já colocaram a dificuldade de situar estas caixas de socorros como entidades operárias, pois elas na verdade são criadas pelos patrôes, suas diretorias têm estes ou seus empregados de confiança nos postos-chaves e freqüentemente a participação é obrigatória. Segundo Tania R. de Luca ( $O$ sonho do futuro assegurado. São Paulo/Brasilia: Contexto/CNPq, 1990) os operários as veriam como um obstáculo à livre organizaçăo da categoria, ineficientes e servindo de fonte de lucros para alguns poucos (p. 50-54). 
a Caixa dos operários da Fábrica Aguiar (coureiros-1894) em Pelotas, enquanto Rio Grande possuía a Associação Mutualidade da Rheingantz, responsável também pela manutenção de escola e banda, existindo desde 1885 .

Havia várias outras entidades beneficentes representativas de nacionalidades ou etnias nas duas cidades, compartilhando o papel de representação social destes segmentos com entidades bailantes, teatrais, carnavalescas, musicais e esportivas. Há indícios concretos da participação operária em entidades recreativas, tanto de forma dispersa e individual, quanto através da existência de várias sociedades bailantes formadas predominantemente por operários ou artesãos. Muitas destas entidades, ao mesmo tempo, desenvolviam atividades teatrais e/ou possuíam grupos carnavalescos, de forma que as possibilidades de participação em atividades culturais e de lazer da classe trabalhadora eram consideráveis, muito provavelmente sobrepujando as existentes hoje, especialmente quanto à forma ativa em que se dava esta participação. Ela envolvia não só a massa operária, mas também suas lideranças, cujos nomes encontram-se presentes em várias diretorias destas entidades naquele período, especialmente nas teatrais ${ }^{10}$. Mesmo líderes socialistas e anarquistas participavam, como Antonio Guedes Coutinho, que era membro confesso de várias entidades bailantes e ator/autor teatral; João Tolentino de Souza, integrante de clubes literários e diretor do Clube Carnavalesco Demócrito (1888) e Alberto Ferreira Rodrigues, que participou das diretorias do Clube Literário Termópylas e do Club Carnavalesco Guarany, no ano de 1888. Guilherme Sauter, também editor do jornal Democracia Social junto com os anteriores, participou do Club de Regatas em 1897. Lucídio Marinho Prestes, jornalista conhecido como anarquista em Porto

10 A participação de militantes socialistas e anarquistas como atores, diretores ou autores de peças teatrais é uma constante presente no movimento operário das duas cidades da época, especialmente em Rio Grande, onde o teatro operário encontrou melhores condiçōes de desenvolvimento, entre outros motivos pela infraestrutura representada pelo palco-salāo da SUO. Tal como na Argentina, "la labor de los integrantes del grupo era asumida como una militancia, demostrada por el hecho de que destacados luchadores sociales intervenían como autores o intérpretes" (KLEIN, Teodoro. "Teatros Anarquistas y socialistas en el 1900". In: Desmemoria/Revista de Historia, ano 3( 9), nov./dic. 1995/ene. 1996, Buenos Aires, p.126-135, p. 130). 
Alegre ${ }^{11}$, em Pelotas foi presidente da sociedade bailante Juventude Democrata e $2^{\varrho}$ secretário da sociedade Musical Republicana, ambas em 1890. Nenhum deles, entretanto, apresentou o fôlego de João Thomas Mignone (ou Giovanni Thomaso Mignoni), artesão sapateiro, sócio gerente de fábrica de calçados e destacado líder socialista em Pelotas. Entre 1888 e 1902, ele participou de cargos variados na diretoria das seguintes entidades: Centro Cooperador dos Fabricantes de Calçados, Congresso Operário, Liga Operária, União Operária Internacional, Sociedade Dramática Filhos do Trabalho, Circolo Italiano Garibaldi, Sociedades Italianas Reunidas Circolo Garibaldi e Unione e Filantropia, Sociedade Italiana 20 de Setembro, e duas lojas maçônicas. Além disso, graças às suas excelentes relaçōes com a Sociedade União Operária de Rio Grande, freqüentemente participava de festas e solenidades na entidade. Sua atividade associativa só não foi maior porque provavelmente foi prejudicada pelas suas idéias socialistas. Assim, nota-se que as chapas para a diretoria da Liga ou da Sociedade Filhos do Trabalho, nas quais ele ocupava uma posição importante, costumavam ser derrotadas, ficando sua participação reduzida à posição de orador ou a presença em cargos menores na diretoria.

Quanto à participação política, houve dois grupos socialistas constituídos na região, um nucleado ao redor do jornal Democracia Social em Pelotas, o qual durou apenas 6 meses, mas consolidou um foco socialista que terá repercussões em diferentes cidades do Estado $^{12}$. E outro na cidade de Rio Grande, tendo como porta-voz inicial o jornal Echo Operário, evoluindo depois para a fundação de um Partido Socialista na cidade $\left(1^{\circ} / 5 / 98\right)$, do qual participaram várias lideranças da Sociedade União Operária. Em 3/5/1902 eles fundaram um Clube Socialista, conseguindo enviar um representante (Guedes Coutinho) ao $2^{\circ}$ Congresso Socialista Brasileiro, em São Paulo ${ }^{13}$. O partido participou de duas eleições na cidade, conseguindo eleger um vereador na primeira, em eleição posteriormente anulada ${ }^{14}$. Em 1900, eles lançaram chapa completa às eleições municipais, conseguindo

11 MARÇAL, J. B. Os anarquistas no Rio Grande do Sul. Porto Alegre: Unidade Editorial, 1995, p. 135-136.

12 Echo Operário, 23/1/1898.

13 Correio Mercantil, $17 / 5 / 1902$ e 17/6/1902.

14 Echo Operário 11/9/1898 e 1/1/1899. 
cada candidato do Partido Socialista exatos 13 votos em cada uma das 5 seções eleitorais urbanas, caracterizando um processo de fraude eleitoral $^{15}$ e expondo claramente os limites permitidos à participação operária pelo sistema político dominante. A partir de então, os socialistas reorientaram-se no sentido de uma maior atividade em relação às questões de educação e conscientização operária, havendo uma maior proximidade, marcada pelo trabalho conjunto em jornais e na SUO, com lideranças anarquistas. Em relação à elite, este partido sempre esteve muito próximo a elementos do Partido Federalista, a tal ponto que seu candidato a vereador em 1898 e a prefeito em 1900 foi Rodolpho José Gomes, membro do partido oposicionista local. Entretanto, o estudo das relações políticas do partido, bem como sua ideologia e demais atividades desenvolvidas, serão objeto de uma análise mais detalhada e aprofundada em outro momento, pois fogem aos limites deste artigo.

\section{Movimentos reivindicatórios}

Os movimentos grevistas nas duas cidades existiram em número muito maior do que se suspeitava e com maior intensidade, conforme pode ser visto nas tabelas anexas. De 1889 a 1901, tem-se um total de 20 greves, sendo 7 em Pelotas e 13 em Rio Grande. Em Pelotas elas possuíram uma dispersão maior, envolvendo autônomos e operários de fábricas, enquanto em Rio Grande, 7 greves ocorreram em setores vinculados ao porto e 3 entre os operários têxteis.

Organização: Das greves de que se tem mais notícias - coincidentemente as primeiras, ambas em $1890^{16}$ : tipógrafos em Pelotas e

15 Por sua vez, cada candidato do PRR local conseguiu 764 votos em cada uma das 5 seções urbanas e 214 votos cada um na seção do Povo Novo (Correio Mercantil, 31/5/1900).

16 Segundo Silvia Petersen ("As greves no Rio Grande do Sul 1890/1919". In: DACANAL, H. \& GONZAGA, S. [orgs.]. RS : economia e política. Porto Alegre: Mercado Aberto, 1979, p. 302) a greve dos tipógrafos foi a primeira de que se encontrou notícia em território gaúcho. Entretanto, houve uma greve anterior, iniciada em $1^{2}$ março de 1890 , dos trabalhadores que construíam a estrada de ferro em Cacequi, entre os km 40 e 60 de Taquarembó, cujas causas foram o atraso de dois meses no pagamento dos salários e os maus tratos do encarregado. A greve foi reprimida pelo $5^{\mathrm{g}}$ Regimento do Exército (Correio Mercantil, 14/3/1890). 
operários da Rheingantz em Rio Grande - surpreende o grau de organização do movimento. Ambas foram precedidas de articulaçōes e reuniōes que definiram as reivindicações, as quais foram encaminhadas através de comissões aos patrões; ambas apresentaram comissão de negociação - sendo que os grevistas da Rheingantz possuíam comissẫo de vigilância para evitar eventuais fura-greves. A abrangência destas greves foi invejável. O movimento da Rheingantz parou totalmente a fábrica, incluindo mulheres e crianças, e durou uma semana. Eles se articularam de forma a visitar redaçôes de jornais, buscando apoio e intermediação na negociaçāo, conseguindo o apoio da opinião pública. Quanto à dos tipógrafos, ela também apresentou um grau de adesão considerável, embora não total, e conseguiram formar canais de auxílio aos grevistas, desenvolvendo formas alternativas de captação de recursos - feitura de trabalhos gráficos a particulares, utilizando as oficinas do A Pátria, jornal que apoiou a greve e cuja redação transformou-se no "quartel general" dos grevistas ${ }^{17}$. Correspondendo-se com tipógrafos de outras localidades, conseguiram impedir a estratégia patronal de contratação de substitutos em outras cidades. Outras greves, como a dos chapeleiros, também demonstraram possuir um grau organizativo elevado, mantendo comissões de negociações e propondo, ao final da greve, a formação de uma entidade representativa da categoria, para fazer frente às inevitáveis demissōes.

Entre as greves em categorias fabris, nenhuma pareceu padecer da falta de organização que uma certa concepção do movimento operário brasileiro tendeu a projetar para essa época. Ao contrário, demonstraram a existência de um proletariado consciente e organizado, conhecedor não só dos mecanismos básicos de uma greve, como também das formas de otimizar suas chances de sucesso. A pergunta óbvia é: como conseguiram essa organização? Não existe ainda uma resposta a ela, mas pode-se avançar algumas hipóteses. Inicialmente, há a constatação de que os primeiros movimentos grevistas não puderam contar com o auxílio de associaçōes, ou por inexistentes, ou por omissas frente aos movimentos. Na greve dos tecelōes da Rheingantz, a SUO não existia e na dos chapeleiros, a Liga sequer se manifestou.

17 A cobertura completa da greve encontra-se nos jornais Correio Mercantil (CM) e A Pátria de Pelotas e Echo do Sul (ES) de Rio Grande, dos dias em que ocorreu o conflito (aproximadamente de 6/4/1890 até 13/4/1890). 
Restam, portanto, as hipóteses de que a experiência e a "técnica" de bem fazer uma greve tenham sido trazidas por operários vindos de outras regiões, ou de que estes tecelões, chapeleiros e tipógrafos tenham se imbuído do conhecimento necessário através da leitura de jornais e livros sobre agitação operária. Esta última não é uma hipótese tão absurda, ao considerar-se que todos os jornais, mesmo os conservadores, costumavam dar amplo espaço à descrição de movimentos reivindicatórios, especialmente aqueles ocorridos na Europa. Na greve dos chapeleiros houve o apoio explícito do grupo socialista vinculado ao jornal Democracia Social, mas, até onde sabemos, era um grupo autóctone, sem o envolvimento de qualquer elemento forâneo.

Quanto à hipótese de ter havido contacto com operários de outras regiões, o porto de Rio Grande constituía-se numa estrada sempre aberta para essas migrações internas, comuns aos militantes operários. Nada sabemos ainda sobre a rede de contactos com o Prata, além de sua existência, mas ela poderia consubstanciar-se em troca de informações, jornais e militantes. Em Pelotas, os operários costumavam desfilar em colunas, o mesmo tipo de formação que se observa no Uruguai. ${ }^{18}$ Sabemos que o fluxo de viajantes era incessante entre o Rio Grande do Sul, a Argentina e o Uruguai, e é provável que houvesse influências do movimento operário platino, mais avançado em relação ao nosso, sobre a classe operária dessa zona de fronteira.

Sucesso: Quanto ao sucesso das greves, estava condicionado a alguns fatores, como grau de repressão enfrentada e nível de articulação da categoria. Surpreende que, embora a grande quantidade de movimentos grevistas detectados no porto (2 em Pelotas, $7 \mathrm{em}$ Rio Grande), a maior parte deles foram derrotados, pela repressão e/ou substituição de grevistas por elementos de outras localidades, demostrando que o grau de organização dos portuários ainda era muito pequeno. Apenas os operários de estaleiros demonstraram maior articulação, na medida que, em ambas mobilizações, o movimento parece ter ocorrido de forma integrada entre Pelotas e Rio Grande e conseguido seus objetivos, com exceção apenas de um estaleiro, em que ocorreram as duas greves, devido à intransigência patronal.

Repressão: A repressão, nestas greves, não teve um papel tão decisivo como em momentos posteriores. Em Pelotas, especialmente,

18 Ver, a respeito, ZUBILLAGA, C. \& BALBIS, J. História del movimiento sindical uruguayo (v. 1). Montevideo: Ediciones de la Banda Oriental, 1985. 
foi pequena a intervenção da polícia nos movimentos. O chefe de polícia, notificado, chamava algumas lideranças grevistas e as argüia sobre questões relativas à manutenção da ordem, especialmente sobre a formação de piquetes. Em Rio Grande, a polícia teve um maior envolvimento com as greves, havendo denúncia de que pressionou mulheres e crianças na greve da fábrica Rheingantz para que voltassem ao trabalho, além de prender um grevista. No porto, entretanto, ela sempre esteve presente, com poder intimidatório e repressivo.

A repressão patronal era forte, basicamente utilizando-se de duas estratégias: demissão de lideranças e substituição de grevistas. Mas, se a primeira era largamente utilizada, a segunda implicava a existência de elementos disponíveis e com qualificação para o trabalho, o que não era tão fácil de encontrar, especialmente para o setor fabril. É talvez isso que explique a confortável situação dos sapateiros vinculados à fábrica Júlio Silva, de Pelotas. Ao desmentir notícia da ocorrência de greve e da conseqüente demissão de sapateiros, eles encerraram sua declaração aos jornais, afirmando que aqueles que saíram da fábrica foram por interesse próprio e frisando que poderiam voltar, se quisessem. Aliás, o sapateiro conduzido à delegacia para prestar esclarecimentos sobre a greve, como suposto líder do movimento, fora buscado pela polícia na nova fábrica em que estava trabalhando.

A greve dos chapeleiros ocorreu em 1893 e obteve sucesso, mas foi precedida de movimento fracassado em maio de 1891, em que pediam reajuste de 25 a $30 \%$ ameaçando com greve, caso não fossem atendidos $^{19}$. Deste episódio, restou uma articulação dos patrões no sentido de não contratarem operários, sem que estes apresentassem um cartão do dono da fábrica da qual saíram. Às vezes, nem sequer é necessário a ocorrência de greve para que haja repressão, como no caso dos operários de um curtume de Pelotas, que pediram descanso aos domingos e feriados e cujo patrão, apesar de conceder a reivindicação, despediu os líderes da mesma ${ }^{20}$.

Reivindicações: As questões salariais (11) e de condições de trabalho (4) imperaram entre os motivos das greves. Algumas foram motivadas por maus tratos pelo mestre ou encarregado, destacando-se entre elas a da Rheingantz e a dos operários da estrada de ferro em Rio Grande, as quais impressionam pela solidez e abrangência do 
movimento, ainda mais considerando-se que eram greves sem motivação econômica direta .

A greve dos operários da fábrica Rheingantz de 1890 derivou sua importância do fato de ser a primeira greve em setor fabril do Estado, numa empresa importante e com um viés paternalista demarcado, marcando a revolta dos tecelóes frente ao comportamento do inspetor que os atormentava com multas abusivas e humilhações, às vezes não lhes passando material para trabalhar (desta forma então havendo uma motivação pecuniária). Ainda houve um marco de solidariedade em sua atitude, pois estavam descontentes com a demissão de um irmão do Rheingantz, que trabalhava como apontador ${ }^{21}$. $\mathrm{O}$ episódio demonstrou claramente o paternalismo com que os operários eram tratados, seja pela imprensa, seja pela direção da fábrica, na hora em que os convida a entrar ao trabalho ("falou-lhes brandamente, mostrando a conveniência de voltarem às suas ocupações" - CM, 9/7/1890). Esse tratamento paternalista refletiu-se também na atitude dos operários que, abrindo mão de sua reivindicação inicial, aceitaram esperar a decisão do patrão Carlos Rheingantz, quando de sua volta da Europa. O fim da greve marcou uma divisão do operariado, pois enquanto a maioria voltou ao trabalho aos poucos, "os melhores operários" não retornaram, havendo a demissão de oito, identificados como líderes ${ }^{22}$.

Houve vários movimentos reivindicatórios que não chegaram à paralisação de atividades, inclusive um de professores municipais em Pelotas, que buscavam aumento salarial. Contudo, a maioria destes movimentos teve por objetivo a luta por melhores condições de trabalho, como aquele dos padeiros, pelo fechamento das padarias aos domingos. Houve também um movimento coletivo entre os médicos de Pelotas, em 1893 pelo qual estes se negaram a continuar atendendo em convênio com as sociedades mutualistas da cidade. Contudo, tal medida não chegou a prejudicar a população (exceto, talvez quanto à requisição de remédios nas boticas conveniadas), pois, como lembrou

\footnotetext{
21 É interessante que a greve dos construtores da estrada de ferro em Cacequi (ver nota acima) também tinha como uma das suas causas a solidariedade a um funcionário graduado despedido pelo encarregado.

22 Correio Mercantil, 9/7/1890 e A Pátria, 8/7/1890.
} 
o próprio Democracia Social, os pobres de Pelotas tinham atendimento em casa - e de graça - pelos melhores médicos da região ${ }^{23}$.

\section{Lutas contra a carestia}

Embora normalmente não sejam consideradas em análises dedicadas à classe operária, as lutas contra a carestia de vida ocupam um lugar importante na vida da classe trabalhadora naquele momento. $\mathrm{Na}$ década de 1890 houve crise econômica e inflação, resultado da política econômica de Rui Barbosa, que elevou o custo de vida e inflacionou a moeda, além de provocar efeitos funestos em vários setores da economia. Houve falta de dinheiro circulante e desemprego, provocado inicialmente pelas conseqüências do Encilhamento e depois pelas medidas econômicas tomadas para sanear a economia. Nesta conjuntura, a vida das classes trabalhadoras tornou-se muito mais difícil e dura e seus meios de lidar com a crise eram, obviamente, limitados.

Isso leva a outra constatação importante: a influência da política municipal na vida dos cidadãos comuns naquele momento. Contrariamente ao que acontece hoje, era na órbita municipal que poderiam ou não ser tomadas as principais políticas no controle da elevação do custo de vida, ou seja: pertenciam à esfera municipal a política de controle aos açambarcadores dos gêneros coloniais que abasteciam a cidade; a fixação do preço da carne verde em açougues fiscalizados pelo município; a coibição do uso de vales pelas casas comerciais, para fazer frente a escassez (forjada) de moedas; e o controle do comércio ambulante de alimentos. Em Rio Grande houve lutas contra a carestia e conflitos que envolveram a Intendência em três oportunidades nesta década ${ }^{24}: 1892,1897$ e 1898 . Em Pelotas, o movimento teve menor vulto, mas também ocorreram mobilizações.

É justamente neste tipo de lutas que se nota a articulação dos operários com as lideranças burguesas. Por exemplo, nas lutas realizadas contra o aumento do custo de vida em Rio Grande, no ano de

23 Democracia Social, 22/10/1893. Este fato foi comprovado por outras fontes e parece ter sido comum também em Rio Grande.

24 Em 1892 ocorre um "meeting" popular, protestando contra a ação dos atravessadores de gêneros coloniais (Correio Mercantil, 26/7/1892). Em 1897 a luta foi contra o monopólio do preço do pão e pela manutenção do preço antigo (Opiniāo Pública, 30/3/897). O movimento de 1898 foi contra o preço da carne verde. 
1897, a diretoria da SUO, à frente de bom número de populares, foi recebida pelo prefeito, que se utilizou do estratagema de falar repetida e longamente, com o fito de esvaziar a manifestação, o que terminou ocorrendo. Entretanto, no ano seguinte, quando o movimento novamente se fortalece, a orientação da entidade foi outra. $\mathrm{O}$ fato de o prefeito não ter respondido a um ofício da União em que esta pedia providências com respeito à elevação do custo de vida, deu ensejo a um grande movimento de protesto contra a Intendência, que culminou na realização de um comício em praça pública, sendo aprovada moção exigindo a renúncia do intendente. Nas reuniões preparatórias para o comício, a entidade trabalhou articuladamente com diversos representantes de jornais de oposição da cidade, muitos deles federalistas, incluindo o único orador do comício, João José Cézar ${ }^{25}$. Ou seja, a SUO era uma entidade operária, mas trabalhava articuladamente com a oposição burguesa em assuntos de seu interesse. Mas também ocorria de ver-se a entidade junto ao governo, seja pedindo-lhe concessões, como um subsídio financeiro para a manutenção da aula do sexo feminino, seja liderando um movimento pela construção dos molhes da Barra do Rio Grande, em perfeita sintonia com os governantes municipais. Aliás, foi ao governador castilhista Borges de Medeiros que ela recorreu pedindo garantias para a realização do comício contra o intendente, também castilhista, de Rio Grande.

\section{$01^{\circ}$ de Maio}

Não poderia faltar, num artigo sobre o movimento operário, um ponto especial sobre as comemorações de $1^{\circ}$ de Maio. Esta era a grande festa operária, na qual as entidades jogavam seus esforços no sentido de marcar a força numérica da classe e seu potencial de transformação. Ao lado desta, comemoravam também as grandes datas cívicas, como o 13 de maio, 7 e 20 de setembro, 12 de outubro, 15 de novembro e algumas, como a Liga, o 14 de Julho. As duas cidades responderam rápido ao apelo do operariado internacional para come-

25 O episódio do $2^{2}$ comício está relatado em A Gazetinha, 30 e 31/8/1898, $1^{2}$ e 9/9/1898; Echo Operário, nª 104 e dos dias 4 e 11/9/1898; Opiniāo Pública, 22/7/1898 (ofício da União), e dias $6,8,10,12$ e 13/9/1898. O comício ocorreu dia 11/9/1898. 
morar o dia $1^{\circ}$ de Maio. Pelotas fez sua primeira comemoração em 1893, com salva de tiros ao alvorecer e sessão solene à noite ${ }^{26}$. A Sociedade União Operária de Rio Grande foi inaugurada oficialmente no $1^{\circ}$ de maio de $1894^{27}$. A partir de 1896 , a data passou a ser comemorada com grandes manifestações públicas, que incluíam várias salvas de tiro, marcha cívica com visita a jornais à tarde e sessão solene à noite. As entidades costumavam pedir às fábricas e comércio em geral que dessem feriado nesse dia aos seus operários, numa prática que terminou sendo atendida pela maioria. A comemoração em Rio Grande neste ano é a maior já vista, sendo calculada pelos jornais em cerca de 1.600 pessoas, sendo 600 sócios da União e mais de 1.000 operários que se incorporaram ao desfile. Por outro lado, o espírito da comemoração tinha um nítido caráter socialista naquela cidade, como se nota na descrição do evento pelo conservador jornal Echo do Sul: "tomando a [ rua ] Marechal Floriano, a multidāo seguiu, erguendo entusiásticos vivas ao $1^{\circ}$ de Maio, à Revoluçäo Social, ao socialismo, à confraternização da família operária e outros" 28 . Para os anos seguintes, a comemoração vai se sofisticando e se estendendo ao longo de dois a três dias. Em Pelotas a maior mobilização é alcançada no ano de 1897, seguindo o padrão da rio-grandina, mas agregando um piquenique no bairro Fragata entre as comemorações. Em 1898 as comemorações são muito fracas, crescendo de ímpeto novamente para 1899, 1900 e os primeiros anos do novo século, quando vai ocorrer uma singular simpatia pela data nos jornais locais, que passam a dedicar-lhe longos e inflamados editoriais, o que coincide com a participação de seus proprietários e diretores na presidência da Liga. A União Operária Internacional participava de forma independente das comemorações e várias outras entidades operárias, especialmente as bailantes, passaram a comemorar de forma própria a data a partir de 1899 .

* * * *

26 Diário Popular, 28/4/1893 e 3/5/1893.

27 Inaugurou-se "com a primeira manifestação de caráter socialista que se fez no Rio Grande, chamando deste modo sobre si a atenção pública" (Rio Grande do Sul, Revista Ilustrada, $\mathrm{n}^{2} 7$, ano 1 , junho de 1911). 
GREVES EM PELOTAS E RIO GRANDE DE 1889 A 1901 GREVES RIO GRANDE

\begin{tabular}{|c|c|c|c|}
\hline CATEGORIA & DATAS & REIVINDICAÇÖES & RESULTADO \\
\hline $\begin{array}{l}\text { FOGUISTAS } \\
\text { VAPOR INGLES } \\
\text { COMETA }\end{array}$ & $23 / 1 / 89$ & $\begin{array}{l}\text { AUMENTO } \\
\text { SALARIAL }\end{array}$ & $\begin{array}{l}\text { PRISÃO GREVIS- } \\
\text { TAS A PEDIDO } \\
\text { DO CÔNSUL }\end{array}$ \\
\hline $\begin{array}{l}\text { JORNALEIROS } \\
\text { ARTISTA } \\
\end{array}$ & $17 / 5 / 90$ & ??? & \\
\hline $\begin{array}{l}\text { TECELŌES } \\
\text { RHEINGANTZ }\end{array}$ & $\begin{array}{l}30 / 6 / 90 \text { OU } 1 / 7 / 90 \\
\text { FIM 7/7/90 }\end{array}$ & $\begin{array}{l}\text { DEMISSĀO } \\
\text { INSPETOR }\end{array}$ & $\begin{array}{l}\text { DEMISSÃO LÍDE- } \\
\text { RES AGUARDAM } \\
\text { VOLTA PATRĀO }\end{array}$ \\
\hline $\begin{array}{l}\text { MARINHEIROS - } \\
\text { PAQUETE } \\
\text { DESTERRO } \\
\end{array}$ & $5 / 7 / 90$ & $\begin{array}{l}\text { BRIGA COM } \\
\text { COZINHEIROS }\end{array}$ & \\
\hline $\begin{array}{l}\text { OPERÁRIOS } \\
\text { ESTALEIRO } \\
\text { TOUGUINHA } \\
\end{array}$ & REF: $10 / 4 / 91$ & $\begin{array}{l}\text { RECLASSIFICAÇÃO } \\
\text { SALARIAL }\end{array}$ & \\
\hline $\begin{array}{l}\text { OPERÁRIOS } \\
\text { ESTALEIRO } \\
\text { TOUGUINHA } \\
\end{array}$ & SETEMBRO 92 & $\begin{array}{l}\text { AUMENTO } \\
\text { SALARIAL }\end{array}$ & $\begin{array}{l}\text { POSSÍVEL } \\
\text { VITÓRIA }\end{array}$ \\
\hline $\begin{array}{l}\text { OPERÁRIOS ES- } \\
\text { TRADA FERRO }\end{array}$ & $28 / 11 / 94 \quad 29 / 4$ & $\begin{array}{l}\text { MAU TRATAMENTO } \\
\text { PELO MESTRE }\end{array}$ & SUCESSO \\
\hline $\begin{array}{l}\text { TRABALHADORES } \\
\text { ALFÂNDEGA }\end{array}$ & 12 A $17 / 10 / 95$ & AUMENTO DIÁRIA & \begin{tabular}{|l} 
VOLTARAM \\
PARA NÃO HAVER \\
DEMISSÕES \\
\end{tabular} \\
\hline $\begin{array}{l}\text { OPERÁRIOS } \\
\text { CONSTRUÇĀO } \\
\text { FÁB. TECIDOS } \\
\end{array}$ & DEZEMBRO 95 & $\begin{array}{l}\text { AMPLIAÇÃO } \\
\text { HORÁRIO ALMOÇO }\end{array}$ & ACORDO \\
\hline CATRAIEIROS & REF. $28 / 5 / 97$ & $\begin{array}{l}\text { REVOLTA REGRAS } \\
\text { ALFÂNDEGA }\end{array}$ & $\begin{array}{l}\text { REPRESSÃO } \\
\text { POLICIAL }\end{array}$ \\
\hline $\begin{array}{l}\text { TECELÕES ITALO } \\
\text { BRASILEIRA }\end{array}$ & $\begin{array}{l}15 / 9 / 97 \\
\text { FIM :25/9/97 }\end{array}$ & $\begin{array}{l}\text { DIMINUIÇÃO } \\
\text { HORÁRIO } \\
\text { CONDIÇŌES } \\
\text { PAGAMENTO. } \\
\end{array}$ & SUCESSO PARCIAL \\
\hline ESTIVADORES & $\begin{array}{l}\text { 1/2/98 } \\
\text { FIM: } 6 / 2 / 98\end{array}$ & AUMENTO DIÁRIA & $\begin{array}{l}\text { FRACASSO: PELO- } \\
\text { TENSES VIERAM } \\
\text { SUBSTITUIR } \\
\end{array}$ \\
\hline $\begin{array}{l}\text { TECELŌES ITALO } \\
\text { BRASILEIRA }\end{array}$ & FIM: $10 / 4 / 01$ & $\begin{array}{l}\text { AUMENTO } \\
\text { SALÁRIOS }\end{array}$ & FRACASSO? \\
\hline
\end{tabular}


GREVES PELOTAS

\begin{tabular}{|c|c|c|c|}
\hline CATEGORIA & DATAS & MOTIVO & RESULTADO \\
\hline TIPÓGRAFOS & $\begin{array}{l}\text { INICIO } 7 / 4 / 90 \\
\text { FIM: } 10-12 / 4 / 90\end{array}$ & $\begin{array}{l}\text { AUMENTO } \\
\text { SALARIAL }\end{array}$ & $\begin{array}{l}\text { SUCESSO } \\
\text { PARCIAL }\end{array}$ \\
\hline ESTIVADORES & $\begin{array}{l}\text { 11/4/91 } \\
\text { FIM: } 18 / 4 / 91\end{array}$ & $\begin{array}{l}\text { AUMENTO } \\
\text { DIÁRIA }\end{array}$ & FRACASSO \\
\hline CATRAIEIROS & $\begin{array}{l}30 / 8 / 90 \\
\text { FIM 1/9/90 }\end{array}$ & $\begin{array}{l}\text { MONOPÓLIO } \\
\text { DO } \\
\text { TRANSPORTE }\end{array}$ & SUCESSO \\
\hline CHAPELEIROS & 8 E $9 / 8 / 93$ & $\begin{array}{l}\text { AUMENTO } \\
\text { SALARIAL }\end{array}$ & SUCESSO \\
\hline CARROCEIROS & $\begin{array}{l}2 / 10 / 93 \mathrm{~A} \\
5 / 10 / 93 \\
\end{array}$ & $\begin{array}{l}\text { AUMENTO } \\
\text { IMPOSTOS }\end{array}$ & $\begin{array}{l}\text { AUMENTO } \\
\text { FRETES }\end{array}$ \\
\hline $\begin{array}{l}\text { SAPATEIROS } \\
\text { FAB. JULIO } \\
\text { SILVA }\end{array}$ & FIM 17/5/96 & $\begin{array}{l}\text { CATEGORIA } \\
\text { NEGA GREVE } \\
? ? ? ?\end{array}$ & \\
\hline TELEFÔNICOS & 23 E $24 / 12 / 97$ & $\begin{array}{l}\text { AUMENTO } \\
\text { SALARIAL }\end{array}$ & $\begin{array}{l}\text { DEMISSĀO } \\
\text { GREVISTAS }\end{array}$ \\
\hline
\end{tabular}

\section{Fontes}

Jornais semanais ou quinzenais: Uniāo Caixeiral (1896) e A Defesa (1904-1905), vinculados ao Club Caixeral, Pelotas; Revista Sul do Brasil (1887-1888); O Bisturi (Rio Grande, 1891-1892); Echo Operário (Rio Grande, 1896-1901); Democracia Social (Pelotas, 1893); A Gazetinha (Porto Alegre,1896-1898).

Jornais diários: Correio Mercantil (Pelotas, 1888-1900); A Pátria (Pelotas, 18881891); Diário de Pelotas (1888-1889); Opinião Pública (Pelotas, 1893-1900); Diário Popular (Pelotas, 1891-1900); Echo do Sul (Rio Grande, 1888-1895); Onze de Junho (Pelotas, 1888-1890). 